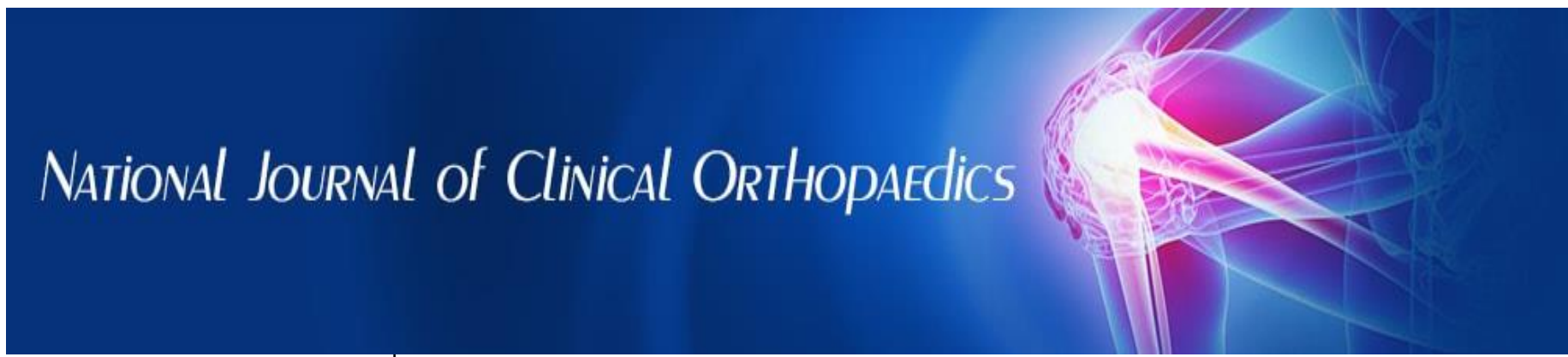

ISSN (P): 2521-3466

ISSN (E): 2521-3474

(C) Clinical Orthopaedics

www.orthoresearchjournal.com

2020; 4(1): 93-94

Received: 12-11-2019

Accepted: 16-12-2019

Dr. Rammanohar Surepally Junior Resident, Department of Orthopaedics, Sri Devaraj Urs Medical College, Tamaka, Kolar, Karnataka, India

Dr. Eswara Reddy G

Assistant Professor, Department of Orthopaedics, Sri Devaraj Urs Medical College, Tamaka, Kolar, Karnataka, India

Dr. Nagakumar JS

Professor, HOU, Department of Orthopaedics, Sri Devaraj Urs

Medical College, Tamaka, Kolar, Karnataka, India

Dr. Madamanchi Harsha Senior Resident, Department of Orthopaedics, Sri Devaraj Urs Medical College, Tamaka, Kolar, Karnataka, India
Corresponding Author: Dr. Eswara Reddy G Assistant Professor, Department of Orthopaedics, Sri Devaraj Urs Medical College, Tamaka, Kolar, Karnataka, India

\section{Comparison of nonoperative modalities in treating cervical spondylosis}

\author{
Dr. Rammanohar Surepally, Dr. Eswara Reddy G, Dr. Nagakumar JS \\ and Dr. Madamanchi Harsha
}

DOI: https://doi.org/10.33545/orthor.2020.v4.i1b.205

\section{Abstract}

Introduction: Pain in the cervical region is one of the major orthopaedic problem. It causes unhappiness to surgeon and patient both. This study is to analyse the different non-operative treatment modalities for the cervical pain.

Purpose of the study: To compare the clinical outcome of cervical spondylosis treated with different non-operative methods.

Methods: The study conducted between October 2018 to April 2019 involve patients with cervical pain visiting orthopaedic OPD. Patients were divided into 3 groups involving a) Neck muscle strengthening exercises (NMS) b) Pharmacological regime c) Combined muscle strengthening and drug regime (CMD). Results: On analysis of results with 90 patients each in group a, b, and c, the patient relief was higher in group c planned for CMD regime followed by group $\mathrm{b}$ and group $\mathrm{a}$ in decreasing order of response rate.

Conclusion: Neck pain being one of the very common disease and its nonresponse to treatment is the reason not to trust the doctor by the patient. We concluded that among the different methods, combined muscle strength and drug regime given best results in majority of cases. And also this CMD regime is easy to follow and cheap compared to other nonoperative treatment modalities.

Keywords: Cervical neck pain, non-operative, treatment, modalities

\section{Introduction}

Pain in the cervical region is one of the major reason affecting many patients irrespective of age ${ }^{[1]}$. Cervical spondylosis may be asymptomatic or can present as posterior neck pain, radioation to suprascapular area or to the whole upper limb upto the hand ${ }^{[2,3]}$. Cervical spondylosis with an incidence of $85 \%$ over the age of sixty and $50 \%$ over the age of $40{ }^{[4]}$. There are so many pathologies lead to cervical pain from extravertebral to intravertebral origin. Trauma, degeneration, malignancy, disc prolapse, infection, inflammation, pharyngitis tonsillitis, etc. ${ }^{[5,6]}$. Various treatment modalities are present to treat cervical pain from nonoperative to operative. Eventhough there are so many treatment methods available for to treat cervical neck pain but nothing proved the best. Initially the nonoperative modalities are usually the most appropriate management ${ }^{[7,8]}$. The operative treatment is for severe neck pain with radiculitis to upperlimb and failed nonoperative treatment ${ }^{[9]}$. Now a day's operative treatment for cervical neck pain are being used to get rid of the pain early. But the results are not satisfactory ${ }^{[10]}$. The main goals for the treatment of cervical neck pain is, to make pain free as early as possible and to allow daily activities without difficulty.

This creates interest in us for the comparison of nonoperative treatment modalities in treating the cervical neck pain for better management in order to prevent the long term complications.

\section{Aims and objectives}

To compare the clinical outcome of cervical spondylosis treated with non-operative modalities.

\section{Material and Methods}

A prospective study of 192 patients with cervical neck pain attended at our hospital ie RL Jallappa Hospital, Tamaka, Kolar, Karnataka, India between July 2018 to April 2019. Written informed consent obtained from each patient and then enrolled in the study based on inclusion 
and exclusion criteria. Local hospital ethics committee approval for the study was granted prospectively. Patients age from 35 years to 75 years with cervical neck pain more than 3 weeks with or without radiculitis duration were included. Patients with history of trauma, inflammatory conditions, infections and malignancy were excluded in this study.

For to assess the patient relief level a questionnaire was made and were ask to quantify the amount of relief as per the table 1 . Increasing score predicts an increase relief level ${ }^{[11]}$.

Table 1: Questionnarie for patient to know the grade

\begin{tabular}{|c|c|}
\hline Questionnaire & Score \\
\hline No relief at all & 0 \\
\hline Mild relief allowing patient to perform needful routine activities & 1 \\
\hline Moderate relief allowing patient to omit the routine dose of drugs & 2 \\
\hline Pain relief sufficient enough to discontinue pain relieving drugs & 3 \\
\hline $\begin{array}{c}\text { No pain at all for at least 3 months of discontinuation of treatment } \\
\text { No pain at all even after }>\text { 6 months of discontinuation of } \\
\text { treatment }\end{array}$ & 4 \\
\hline
\end{tabular}

All the 192 patients were divided into three groups each include 64 patients and named as group N, group P and group C. Group $\mathrm{N}$ includes patients treated with neck muscle strengthening exercises, Group $\mathrm{P}$ includes patients treated with pharmacological therapy and Group $\mathrm{C}$ includes patients treated with combined muscle strengthening and drug regime. Grades in each group was recorded after a minimum period of 6 months follow up.

\section{Results}

We explained fully to all patients about the questionnaire and grade as shown in table 1. Patients in Group $\mathrm{N}$ treated with neck muscle strengthening exercises as the main treatment and analgesics occasionally. Patients in Group P treated mainly with drugs including analgesics, muscle relaxants and neuropathic medications. Patients in Group $\mathrm{C}$ treated with combined use of drugs and neck muscle strengthening exercises ${ }^{[12]}$.

Table 2: Results of nonoperative treatment modalities

\begin{tabular}{|c|c|c|c|}
\hline Grade & Group n & Group p & Group c \\
\hline Zero & 25 & 7 & 0 \\
\hline One & 22 & 18 & 1 \\
\hline Two & 17 & 39 & 2 \\
\hline Three & 0 & 0 & 12 \\
\hline Four & 0 & 0 & 23 \\
\hline Five & 0 & 0 & 26 \\
\hline
\end{tabular}

Patients had no response even after 6 month of treatment seen twentyfive in Group N and seven in Group P. The maximum grade achieved in Group N, P is second grade.

Group C shows best results with twenty-three patients reaching Grade four and twenty-six patients showing Grade five score with complete relief of symptoms after a period of 6 months of completion of treatment.

\section{Discussion}

Cervical neck pain is one of the most common problem for patient to seek orthopaedic doctor. Because of its idiopathic nature, cervical neck pain is difficult to explain clinically and radiologically. There is currently no single study that fully explains the pathogenesis of cervical spondylosis. Orthopaedic doctors treating the cervical neck pain with different modality. Standard treatment for cervical spondylosis is not given by any literature. Many treatment modalities have been proposed and have yielded different success rates. Therefore, treatment for symptomatic cervical spondylosis remains controversial. We did this study to know the outcome with respect to patient satisfaction by using different nonoperative treatment modalities.

\section{Conclusion}

We concluded by our study that for to treat cervical spondylosis the combined muscle strengthening and drug regime is given the best results compared to other treatment modalities. This combined muscle strengthening and drug regime has an advantage of cost-effectiveness and simplicity. In addition, acceptance by the patients was relatively high and was associated with good patient satisfaction. Limitations of the present study were the small sample size and short follow-up. A larger scale of study with a long term follow-up is still necessary.

\section{Financial support and sponsorship: Nil}

Conflicts of interest: There are no conflicts of interest

\section{References}

1. McNab I. Symptoms in Cervical Disc Degeneration. In: Sherk H, ed. The Cervical Spine, 2nd ed. Philadelphia: Lippincott, 1989, 599.

2. Rao RD, Currier BL, Albert TJ et al., Degenerative cervical spondylosis: clinical syndromes, pathogenesis, and management, Journal of Bone and Joint Surgery-Series A. 2007; 89(6):1360-1378.

3. Lehto IJ, Tertti MO, Komu ME, Paajanen HEK, Tuominen J, Kormano MJ. Age-related MRI changes at 0.1T in cervical discs in asymptomatic subjects, Neuroradiology. 1994; 36(1):49-53.

4. Matsumoto M, Fujimura Y, Suzuki N et al., MRI of cervical intervertebral discs in asymptomatic subjects, Journal of Bone and Joint Surgery-Series B. 1998; 80(1):19-24.

5. Gore D, Sepic S, Gardner G, Murray M. Neck Pain: A Long Term Follow-up of 205 Patients. Spine. 1987; 12:1.

6. Montgomery D, Brower R. Cervical Spondylotic Myelopathy Clinical Syndrome and Natural History. Orthop Clin North Am. 1992; 23:487.

7. Dillin W, Booth R, Cuckler J, Balderston R, Simeone F, Rothman R. Cervical radiculopathy (review), Spine. 1986; 11:988-991.

8. Saal JS, Saal JA, Yurth EF. Nonoperative management of herniated cervical intervertebral disc with radiculopathy, Spine. 1996; 21(16):1877-1883.

9. Chesnut RM, Abitbol JJ, Garfin SR. Surgical management of cervical radiculopathy: indication, techniques, and results, Orthopedic Clinics of North America. 1992; 23(3):461-474.

10. Simmons E, Bhalla S. Anterior Cervical Discectomy and Fusion. J Bone Joint Surg Br. 1969; 51:255.

11. Anil Gupta, Prince Raina, Nital Gupta, Mohinder Singh et al., Idiopathic Cervical Pain: Analysis of Various Treatment Modalities. Journal of Evolution of Medical and Dental Sciences. 2015; 4(36):6269-6272.

12. Nolan J, Sherk H. Biomechanical Evaluation of the Extensor Musculature of the Cervical Spine. Spine. 1988; 13:9. 